\title{
Urban form indicators as proxy on the noise exposure of buildings
}

\author{
Lígia T. Silva ${ }^{\mathrm{a}, *}$, Marta Oliveira ${ }^{\mathrm{a}}$, José F. Silva ${ }^{\mathrm{b}}$ \\ ${ }^{a}$ Department of Civil Engineering, University of Minho, Braga, Portugal \\ ${ }^{\mathrm{b}}$ School of Technology and Management, Polytechnic Institute of Viana do Castelo, Viana do Castelo, Portugal
}

\section{A R T I C L E I N F O}

\section{Article history:}

Received 28 November 2012

Received in revised form 22 July 2013

Accepted 24 July 2013

Available online 27 September 2013

\section{Keywords:}

Noise

Exposure

Buildings

Urban form

\begin{abstract}
A B S T R A C T
The present paper aims to address the problems of the urban environment as an area of interaction between urban forms and urban noise. This interaction is intended to be monitored using urban indicators, by comparing the effects of noise propagation using models of urban forms. The model of noise prediction allowed developing noise studies in facades, resulting in noise levels in a calculation grid located in the building facades. The study will allow the creation of different scenarios and anticipate as early as in the preliminary building design phase, which facades would be exposed to higher noise levels. The effects of noise in facades can then be minimized in advance, by adjusting the layout of the urban typology.
\end{abstract}

(c) 2013 Elsevier Ltd. All rights reserved.

\section{Introduction}

In 1972, the United States Environmental Protection Agency (EPA) [1] stated noise as a pollutant and identified it as one of the most common problems that affects the quality of life in urban areas. As a result, in recent decades, some important actions have been developed for the assessment of noise in urban communities. Later in 1980, EPA [1] established criteria to protect the health and well-being in communities in the US, while for the same purpose the World Health Organization [2] in 1993, also published some recommendations on this matter.

The European Commission created, in 1998, a network of EU experts in order to assist in the development of European noise regulation. In 2002, the European Parliament and Council adopted the European Environmental Noise (Directive 2002/49/EC). This directive represented an important step for monitoring urban noise, requiring EU member states to produce strategic noise maps for major sources of noise pollution for all agglomerations with more than 250,000 inhabitants [3]. The deadline to ensure the production of these maps was programmed for 2007 and some results of this Directive already exist, as well as some active action plans by the European Commission for the Environment, which are available online. Some examples of these transpositions are the noise maps for the cities of Augsburg, Birmingham, Brussels, Helsinki, London and Paris.

\footnotetext{
* Corresponding author. Address: Department of Civil Engineering, University of Minho, Campus Gualtar, 4710 Braga, Portugal. Tel.: +351 253 604726; fax: +351 253 604721.
}

E-mail address: Isilva@civil.uminho.pt (L.T. Silva).
In Portugal, the recent transposition of Directive 2001/42/EC on Strategic Environmental Assessment presents new challenges and opportunities in the field of environmental noise. The introduction of the General Regulations of Noise [4] initiated the development of Municipal Plans for Noise Reduction, according to the same regulation, and more than 200 municipalities already have a Municipal Noise Map.

Environmental noise is understood as a significant factor of impact on personal well-being. One of the main challenges of urban planning is the creation of urban spaces capable of providing its residents a high quality of life [5].

Although the exposure of communities to environmental noise is a global concern, most cities are still subjected to noise levels that disturb human activity. Many studies have already proven that noise is largely responsible for many risk factors for physical and mental health in humans. Temporary or permanent loss of hearing, loss of sleep, stress, irritability are other discomforts subsequent to its exposure, as mentioned by Björkman [6] and Lercher [7].

Currently the United States Environmental Protection Agency [1] considers noise as an environmental problem affecting the largest number of people on the planet, after air and water pollution. This problem has proved to be difficult to control due to the existence of a wide variety of sources, methods of assessment of noise exposure or indicators that can undoubtedly describe noise.

The importance of urban form on sustainable development has been recognized in recent years. Since the late 20th century, a number of countries have adopted urban form policies in environmental planning (National Physical Planning Agency) [8]. Urban form directly affects habitat, ecosystems, endangered species and 
water quality through consumption, fragmentation and replacement of natural cover with impervious surfaces. Urban form also indirectly affects travel behavior, which in turn, affects air quality, global climate and noise [9].

However, several studies have focused on the modeling of air pollution and modeling noise in different urban forms [9-17].

Particularly, Lee et al. [10] considered the evaluation of environmental noise through noise mapping and prediction useful, as it allows to view and to quantify environmental noise, contributing to an appropriate planning of the urban sound environment. The main objective of the study was to determine how the interaction between sound sources and urban form influence noise, in a given environment.

Tang and Wang [9] stated that the urban forms in historical areas with narrow roads, complex road networks and a higher density of intersections lead to lower traffic volumes and thus lower noise pollution. Furthermore, Guedes [11] concluded that the urban form with narrow roads, dense road networks and complex intersections leads to a decrease in traffic volume which in turn reduces noise pollution. However, Guedes considered necessary additional corrections to take into account the effects of absorbent ground cover, the settings of the streets, and the distance between the source line and the receivers located in front of a building.

The studies carried out by Lee et al. [10] and Guedes [11] showed the need for further studies on noise pollution and its consequences for the environment and for humans. Later Guedes et al. [12] concluded that the physical characteristics of the urban shape, such as the density of construction, the existence of open spaces, and the shape and physical position of the buildings have significant influence on environmental noise.

Oliveira and Silva $[13,14]$ studied the variation of noise levels in facades at different floor levels (2, 4 and 8 floors) in three different theoretical urban forms (urban forms with concavities, convexities and absence of saliencies). The results showed a small decrease of $L_{\text {eqmax }}$ and average $L_{e q}$ with increasing number of floors. In the case of $L_{\text {eqmin }}$, this trend is reversed.

Salomons and Pont [15] studied the relation between the spatial distribution of traffic noise in a city and the urban density and form, and traffic elasticity for two cities (Amsterdam and Rotterdam) and for various idealized urban fabrics. The results showed that the shape of buildings blocks has a large effect on the sound level.

Wang and Kang [16] studied the variation of noise distribution and how it is influenced by urban morphological characteristics in two cities with different urban densities. A comparative study was carried out between Greater Manchester in the UK and Wuhan in China. The analysis of correlations showed that the urban morphological indices generally have considerable effects on noise levels, with different patterns in the two cities.

Souza and Giunta [17] modeled in an Artificial Neural Networks platform the influence of FSI on the sound environment of streets. The identification of the significance of the relationship between FSI and urban noise was the main output of the research.

From the above considerations, it can be stated that urban parameters that quantify the urban form represent an important issue for decision-makers. Usually these parameters are applied for land use management, but are not necessarily considered in traditional models. Consequently, results of its application are not directly used as an input for decisions. Based on these facts, the general objective of this paper is to analyze the noise levels of several urban areas by assuming them as a function of several urban indices. In this work, three indices routinely used in general planning (compactness index, porosity index and fractal index), constitute some of the input variables in noise analysis. These variables were selected with the purpose of verifying its ability to be used as tools for urban acoustics planning.

\section{Urban forms}

Urban form can be defined as the spatial pattern of human activities at a certain point in time. The conception of urban typologies refers to the arrangement, appearance and functionality of the building and especially to the concept and usage of the urban space.

\subsection{Urban form indicators}

In an attempt to characterize urban forms, several recent classifications have emerged as a mean of quantitative methods $[9,18-$ 23].

Tang and Wang [9] clearly identified four historic and modern urban forms within a very small urban area of less than $10 \mathrm{~km}^{2}$ using geographical information systems (GIS) to extract and analyze over a thousand sets of data on building height and road width, in front of individual buildings in the Macao Peninsula, a world heritage city recognized by the United Nations. Other urban form indicators such as road network geometry, undeveloped lot space, building lot space, road space, green space, hill/water coverage, and land consumption per capita also showed identical characteristics in each urban form.

Torrens and Marina [18] captured eight dimensions of expansion: density, continuity, concentration, clustering, centrality, nuclearity, mixed uses, and proximity. Wassmor [19] has created an expansion index based on four factors (i.e., residential density, mixed neighborhood, business strength and accessibility) for US cities. Galster et al. [20] used four quantitative variables (i.e. metropolitan size activity, intensity, degree distribution and degree of clustering) to differentiate compactness" of expansion. Others, such as Ewing et al. [21], Tsai [22] and Longley and Mesev [23], employed multidimensional indicators to measure the "compactness" in specific neighborhoods or cities.

So far, these methods remain limited to individual cases and studies or specific national contexts, usually within the developed countries.

The indicators intended to be studied have a dimensional nature. The indices described above, although used for various purposes, are spatial metrics that can be applied to various urban forms. The metric space is a concept that generalizes the concept of distance and geometric shapes. The spatial metrics to be used and applied to the selected models will be presented below.

The Compactness Index $(\mathrm{CI})$ measures not only the shape of the urban patch, but considers fragmentation of the global urban landscape [24].

The Compactness index $(\mathrm{CI})$ is calculated based on the following equation:

$\mathrm{CI}=\frac{\sum i \frac{p_{i}}{p_{i}}}{n}=\frac{\sum i 2 \pi \sqrt{\frac{s_{i}}{\pi} / p_{i}}}{n}$

where $s_{i}$ is the patch area $\left(\mathrm{m}^{2}\right), p_{i}$ is patch perimeter $(\mathrm{m}), P_{i}$ is circle perimeter with an area $s_{i}(\mathrm{~m})$ and $n$ is total number of patches (-).

An urban area has higher values of $\mathrm{CI}$ for more regular and more compact urban forms [24].

Porosity Index or Ratio of Open Space (ROS) is the permeability indicator which measures the proportion of open space, compared to the total urban area.

The Index of Porosity or Ratio of Open Space is, according Huang et al. [25], calculated from Eq. (2) shown below:

$\mathrm{ROS}=\frac{s^{\prime}}{\sum_{i} s_{i}} \times 100$

where $s^{\prime}$ is the sum of area of all the open spaces within the urban studied area $\left(\mathrm{m}^{2}\right)$ and $s_{i}$ is patch area $\left(\mathrm{m}^{2}\right)$. 
An urban area consisting of urban forms with higher open spaces has higher levels of ROS. This indicator is also called as the ratio of open spaces.

The Complexity of the Perimeter Index (Fractal) is defined by the perimeter fractal dimension. This index describes the complexity of the perimeter of an urban area through the relationship between perimeter and area [26,27]. In this research, the average fractal dimension of urban patches weighted by the area was used.

The value of fractal dimension is between 1 and 2 . Lower values are obtained when the patch has a simpler form. If the perimeter is more complex and irregular, the fractal dimension will be greater.

The Fractal index (Fractal) is calculated according to Eq. (3) shown below:

Fractal $=\sum_{i=1}^{n}\left(\left(\frac{2 \ln \left(\frac{p_{i}}{2 \sqrt{\pi}}\right)}{\ln \left(s_{i}\right)}\right)\left(\frac{s_{i}}{\sum_{i=1}^{n} s_{i}}\right)\right)$

where $s_{i}$ is the patch area $\left(\mathrm{m}^{2}\right), p_{i}$ is patch perimeter $(\mathrm{m})$ and $n$ is number of patches $(-)$.

\section{(a)}

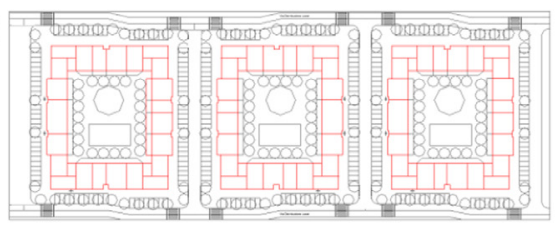

(c)

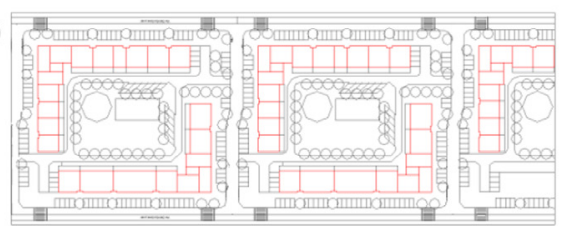

(e)

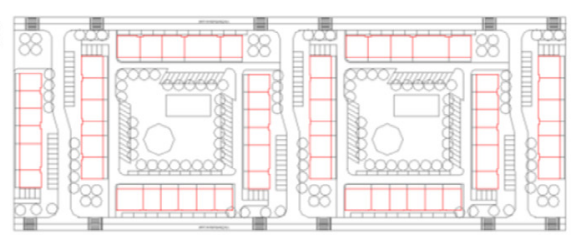

(g)

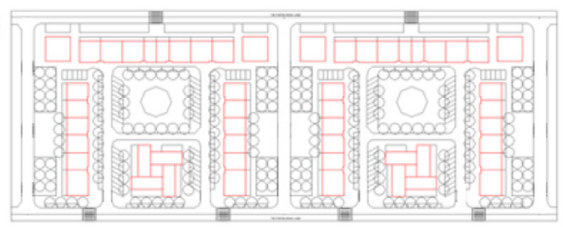

(i)
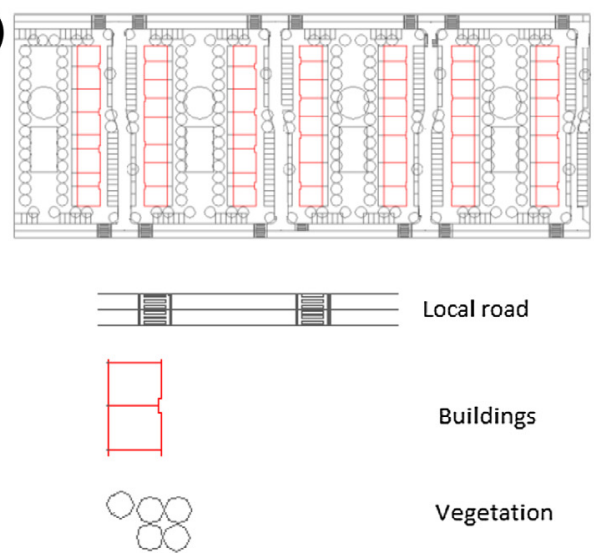

Buildings
The urban indexes and spatial metrics will be applied to types of urban forms, presented in a theoretical model, the "Neighborhood Proximity Model" of João Branco Pedro [28].

\subsection{Theoretical model of neighborhood proximity}

The urban form is defined by the relationship between outside space and buildings volume that exists in a specific soil or landscape. In order to consider various types of urban forms, the classification proposed by Pedro [28] was adopted. Pedro proposes a typological classification of neighborhood proximity (residential unit functionally and spatially organized around an outdoor space, where neighborhood residents tend to establish relationships) based in one programmatic perspective and morphological perspective:

- The programmatic perspective, which is defined as sets of neighborhoods proximities, with identical functional programs.

(b)

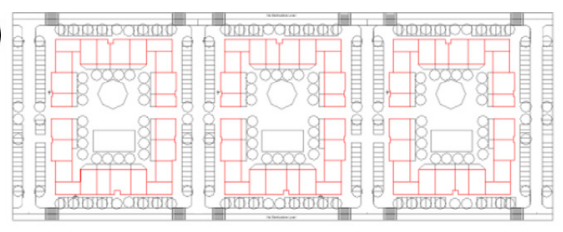

(d)

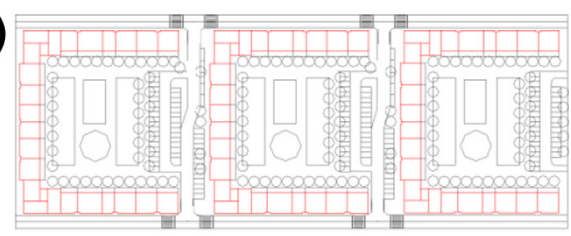

(f)

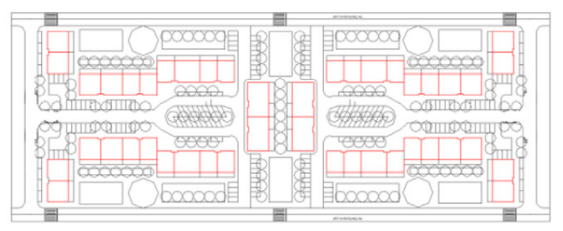

(h)

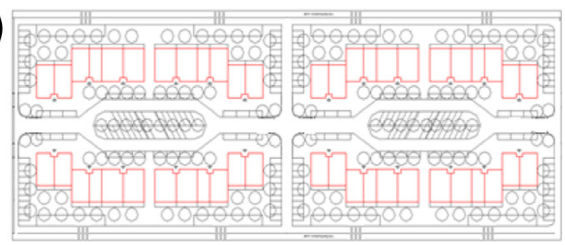

(j)

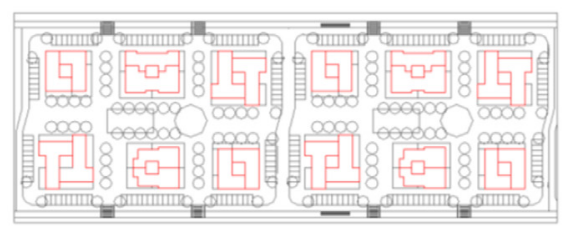

Fig. 1. Urban form (a) 1, (b) 2, (c) 3, (d) 4, (e) 5, (f) 6, (g) 7, (h) 8, (i) 9 and (j) 10. 
Table 1

Physical characteristics of the selected urban forms.

\begin{tabular}{|c|c|c|c|c|c|c|c|}
\hline Urban forms & Patch number & Patch area $\left(\mathrm{m}^{2}\right)$ & Number of patches & Patch perimeter $(\mathrm{m})$ & Radius circle (m) & Occupied area $\left(\mathrm{m}^{2}\right)$ & Reference area $\left(\mathrm{m}^{2}\right)$ \\
\hline Form 1 & Patch 1 & 2110.7 & 3 & 430.1 & 43.48 & 6332.1 & 24707.5 \\
\hline \multirow[t]{2}{*}{ Form 2} & Patch 1 & 1099.1 & 3 & 242.4 & 36.67 & 6335.8 & 24707.5 \\
\hline & Patch 2 & 1012.8 & 3 & 227.2 & 35.70 & & \\
\hline \multirow[t]{3}{*}{ Form 3} & Patch 1 & 2110.7 & 3 & 430.1 & 43.48 & 5095.0 & 24707.5 \\
\hline & Patch 2 & 1061.6 & 2 & 248.0 & 42.98 & & \\
\hline & Patch 3 & 1000.8 & 2 & 231.6 & 40.92 & & \\
\hline Form 4 & Patch 1 & 1951.1 & 3 & 5853.2 & 447.83 & 5473.0 & 24707.5 \\
\hline \multirow{4}{*}{ Form 5} & Patch 1 & 560.0 & 3 & 135.8 & 28.64 & 5434.0 & 24707.5 \\
\hline & Patch 2 & 521.0 & 3 & 128.0 & 26.72 & & \\
\hline & Patch 3 & 528.0 & 2 & 129.4 & 27.07 & & \\
\hline & Patch 4 & 568.0 & 2 & 137.4 & 29.03 & & \\
\hline \multirow[t]{3}{*}{ Form 6} & Patch 1 & 198.7 & 4 & 61.0 & 11.18 & 4317.6 & 24707.5 \\
\hline & Patch 2 & 722.6 & 4 & 181.6 & 37.37 & & \\
\hline & Patch 3 & 316.3 & 2 & 85.8 & 16.72 & & \\
\hline \multirow[t]{4}{*}{ Form 7} & Patch 1 & 521.0 & 4 & 128.0 & 26.72 & 4805.8 & 24707.5 \\
\hline & Patch 2 & 133.7 & 4 & 46.3 & 8.18 & & \\
\hline & Patch 3 & 710.6 & 2 & 167.2 & 36.15 & & \\
\hline & Patch 4 & 383.0 & 2 & 95.0 & 14.75 & & \\
\hline Form 8 & Patch 1 & 679.0 & 8 & 151.1 & 26.92 & 5432.1 & 24707.5 \\
\hline Form 9 & Patch 1 & 696.2 & 7 & 164.3 & 35.44 & 4873.4 & 24707.5 \\
\hline \multirow[t]{4}{*}{ Form 10} & Patch 1 & 351.7 & 4 & 75.0 & 13.26 & 4803.3 & 24707.5 \\
\hline & Patch 2 & 438.2 & 4 & 101.0 & 15.80 & & \\
\hline & Patch 3 & 362.0 & 2 & 80.4 & 13.50 & & \\
\hline & Patch 4 & 460.0 & 2 & 92.4 & 15.76 & & \\
\hline
\end{tabular}

Table 2

Summary of results of the calculation of the form indicators.

\begin{tabular}{clll}
\hline FormType & CI $(-)$ & ROS $(\%)$ & Fractal $(-)$ \\
\hline 1 & 0.38 & 74.37 & 1.25 \\
2 & 0.49 & 74.36 & 1.20 \\
3 & 0.48 & 80.38 & 1.21 \\
4 & 0.35 & 76.31 & 1.28 \\
5 & 0.62 & 78.00 & 1.15 \\
6 & 0.68 & 82.53 & 1.16 \\
7 & 0.72 & 80.55 & 1.14 \\
8 & 0.61 & 78.01 & 1.15 \\
9 & 0.57 & 80.28 & 1.17 \\
10 & 0.82 & 80.56 & 1.07 \\
\hline
\end{tabular}

- The morphological perspective, which comprises a set of neighborhoods proximities, with similar formal characteristics.

\subsubsection{Areas of neighborhood proximity: project requirements}

At this phase, the design parameters applicable to each of the spaces that compose the neighborhood proximity are presented:

- The road system includes the minimum road hierarchy, the minimum width of the track, and the minimum impermeable components of the infrastructure.

- The residential lots data include the maximum height of buildings and the minimum distance between the facades.

- The green space, on the other hand, corresponds to the minimum area of the lots.

\subsubsection{The urban forms}

In order to ease readability, all forms are given a numerical nominal designation. All forms will be presented highlighting its prototype and then filling by repetition the entire area of reference, which corresponds to the common area of all exposed forms. The urban forms can be observed in Fig. 1.

The data related to the physical characteristics of the corresponding forms was calculated using AutoCAD software and is presented in Table 1.

All selected forms described above were based on João Branco Pedro neighborhood proximity model [28] and in its applicable parameters for the design of each area that include the neighborhood proximity and respect the proposed reticule of the reference area (Area $=24707.52 \mathrm{~m}^{2}$ ).

In order to evaluate the urban layout, a set of quantitative indicators of form and dimension was selected, as mentioned above, capable of quantifying and classifying the selected urban forms. The calculation of the form indicators was performed by using the physical characteristics inserted in Table 1 and Eqs. (1)-(3). The results of the calculations of the form indicators exposed above are summarily given in Table 2 .

\subsection{Urban noise}

Noise can be understood as an unpleasant or annoying sound for human beings. The concept of noise is defined as the variation of atmospheric pressure, within the limits of the range and frequency bandwidth to which the human ear responds. Since the human ear is more sensitive to certain frequencies than others, the level of disturbance is dependent on the spectral content of noise. Thus, the definition of sound pressure level is expressed by the following equation:

$L_{p}=10 \times \log 10\left(\frac{p}{p_{0}}\right)^{2}=20 \times \log 10 \frac{p}{p_{0}}$

where $L_{p}$ is the sound pressure level $(\mathrm{dB}), p$ is real value of sound pressure $(\mathrm{Pa})$ and $p_{0}$ is reference sound pressure and corresponds to the minimum threshold of human hearing $\left(p_{0}=2 \times 10^{-5} \mathrm{~Pa}\right)$.

The environmental noise of urban environment is, regardless of the location, not stationary, as it varies with time, which appears in the signal in the form of peaks and troughs. In most studies dealing with urban noise, the concept of equivalent sound level $\left(L_{e q}\right)$ is a sound descriptor defined as an equivalent continuous noise level, which contains the same amount of energy of noise in a period of time as the actual noise fluctuation over that period of time. It is expressed by the following equation.

$L_{e q}=10 \times \log \left(\frac{1}{t} \int_{0}^{t}\left(\frac{p(t)}{p_{0}}\right)^{2} d t\right)$

where is the $L_{e q}$ is the equivalent continuous sound pressure level $(\mathrm{dB})$ and $t$ is time for measurement (s). 
Still included in the noise indicators, the continuous sound level for periods of days can also be defined. According to the RGR (General Noise Regulations, approved by Decree Law No. 9/2007 of January 17) [4] daytime period is between 7 am and 8 pm, evening corresponds to the period between $8 \mathrm{pm}$ and $11 \mathrm{pm}$ and night time goes from $11 \mathrm{pm}$ to $7 \mathrm{am}$. This regulation defines long-term environmental noise indicators, which are $L_{\text {day }}$ (daytime noise indicator) $L_{\text {evening }}$ (evening noise indicator) and $L_{\text {night }}$ indicator (night noise indicator).

The $L_{\text {day }}, L_{\text {evening }}$ and $L_{\text {night }}$ noise levels should be long-term levels in accordance with ISO1996-2:1987 [30]. These are determined for all daytime, evening and night periods during one year. ISO 1996-2:1987 [29] also defines the long-term average noise level as a equivalent continuous sound pressure level $\mathrm{A}$, which can be determined by calculation. It takes into account variations in the noise source and in the weather conditions that influence the noise propagation.

Noise is emitted by a sound source or a set of sources and spreads from the source in the form of mechanical concentric waves, in a slightly spherical form. Depending on the source, these waves may acquire a spherical, cylindrical or planar form. Noise decreases with increasing distance between the source and the receiver station. This reduction depends on several factors such as the source type, the absorption characteristics of the surrounding soil and the existence of barriers. In addition to what has already been mentioned, the weather conditions also have a strong influence on the propagation of noise. The wind and the temperature are the more significant factors.

The noise prediction method should provide accurate results, which represent the real situation of noise levels under any conditions of emission and propagation [30]. Achieving this depends on the assessment of noise emissions due to traffic flow and the assessment of noise attenuation between the source and the receiver. There are numerous models available in the market for noise prediction, which is an important working tool in modeling the acoustic situation, as reported by Bertellino and Licitra [31]. The method, known as the New Method of Road Traffic Noise Prediction (NMPB 96) was developed in France in 1996. This is an interim method recommended by Directive 2002/49/EC [3] of the European Parliament and the Council of 25th June on the assessment and management of environmental noise. When calculating the propagation of acoustic energy that reaches a specific receptor, several attenuating factors should be considered, namely: geometric divergence, absorption by air, diffraction, effect of soil surface and vertical absorption [11].
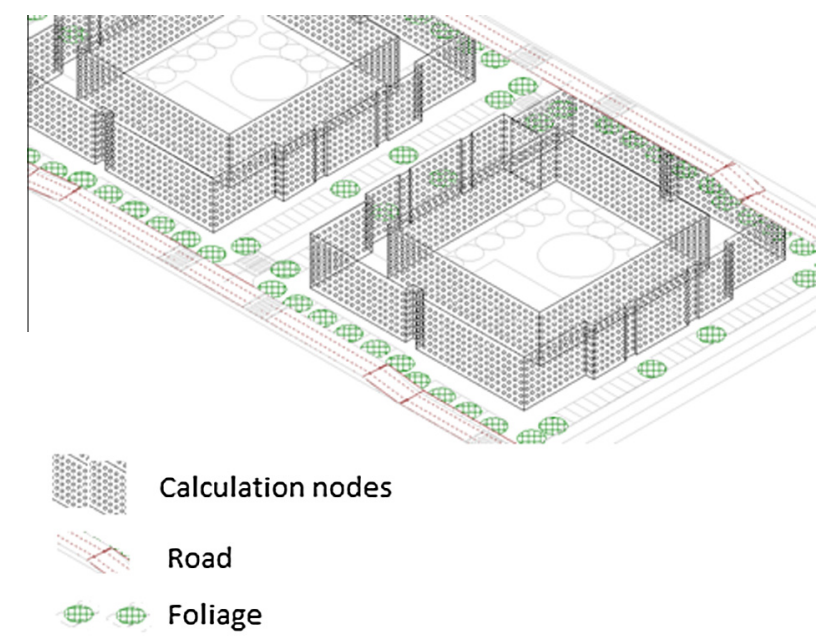

Fig. 2. Calculation square grid on facades of form 1 .
For the development of this research, these applied concepts and fundamentals were taken into account. In the present study, the calculation method NMPB96 with the software CadnaA was used.

\section{The Influence of the urban form on the noise exposure of buildings}

The urban form typologies and indicators previously presented were combined to create several scenarios. Therefore, the submitted urban forms were based on a $210 \mathrm{~m} \times 140 \mathrm{~m}$ grid, with a total gross floor area of $29,400 \mathrm{~m}^{2}$ and a perimeter of $700 \mathrm{~m}$. Each of the scenarios developed is served by two local roads with the following characteristics:

- Asphalt pavement without inclination.

- 300 Total vehicles/h with $5 \%$ heavy vehicles (fluid flow of road traffic).

- Traffic speed of $50 \mathrm{~km} / \mathrm{h}$.

The noise levels were calculated for the 10 urban forms and in order to evaluate the average noise levels at the facades, including all saliencies of all urban forms, the adopted calculation grid comprised a closed mesh. The following calculation parameters were adopted:

- The evaluation of noise level at the facades was developed using a square calculation grid (Fig. 2) on all the facades of $1.5 \mathrm{~m} \times 1.5 \mathrm{~m}$ and a distance from the facade of $0.5 \mathrm{~m}$.

- Reflection order: 2.

- Output: $L_{e q}(\mathrm{~A})$.

- Favorable meteorological conditions to sound propagation.

- Temperature: $15^{\circ} \mathrm{C}$; Humidity: $70 \%$.

- The buildings of the each of the 10 scenarios have the following characteristics:

- Number of floors: 4 floors.

- Height of each floor: $3 \mathrm{~m}$ (ground floor included).

- Total height of each building: $12 \mathrm{~m}$.

The calculation grid in each urban form was generated by CadnaA and followed the characteristics described above. Fig. 2 illustrates the calculation square grid on facades for urban form 1 . In the other urban forms, the method was similar.

The noise level $\left(L_{e q}\right)$ at the buildings facades, in the selected urban form, was calculated for each of the receivers of the calculation grid created for this purpose. The arithmetic average noise level, and the maximum and minimum noise levels were calculated of the 10 urban forms and the resulting values are summarized in Table 3 below.

This approach showed that in the 10 urban forms created, with the same area and noise sources, the arithmetic average noise

Table 3

Summary of results of noise levels.

\begin{tabular}{lllll}
\hline Urban forms & $L_{e q}(\mathrm{dBA})$ & $L_{\max }(\mathrm{dBA})$ & $L_{\min }(\mathrm{dBA})$ & Number of receivers \\
\hline Form 1 & 50.7 & 64.3 & 35.9 & 6216 \\
Form 2 & 50.3 & 64.8 & 35.6 & 6909 \\
Form 3 & 52.9 & 64.2 & 38.0 & 5439 \\
Form 4 & 52.7 & 68.8 & 35.9 & 6489 \\
Form 5 & 54.8 & 63.8 & 44.2 & 6272 \\
Form 6 & 54.7 & 63.1 & 41.1 & 5474 \\
Form 7 & 55.9 & 64.9 & 44.4 & 5866 \\
Form 8 & 51.7 & 63.2 & 35.8 & 6273 \\
Form 9 & 57.1 & 64.1 & 48.9 & 5411 \\
Form 10 & 56.7 & 64.0 & 45.0 & 5250 \\
\hline
\end{tabular}


level, and the maximum and minimum noise levels calculated at the buildings facades are quite different. In order to obtain comparative results and to draw some conclusions on how the urban form can influence the noise exposure of buildings, in the next step, all form indicators will be related with the noise levels of the 10 urban forms (see Figs. 3-5).

With the increase of ROS, the voids between buildings also increase, that is, increases the space for propagation of sound waves reducing quiet areas. As expected, the results obtained show that, with the increase of ROS, the average noise level on the facades of buildings increases.

Regarding Compactness, a compact urban form is a form without irregularities, consequently not allowing the creation of protected areas or shadow zones. As expected, the results obtained demonstrate that, with the increase of the IC, the average noise level on the facades of the buildings increases.

The Fractal Index mainly describes the roughness of the urban boundary. With increasing Fractal Index, the average values of $L_{e q}$ decreases. The obtained variation is consistent with the variation of noise levels in the facades. This is due to the fact that the greater the irregularity of the urban forms, the higher is the possibility of formation of shadow zones, that is, of more protected areas. This fractal dimension approaches the value of one (the fractal dimension of a circle is equal to 1 ), for forms with simple perimeters and approaches the value of two when forms are more complex. An indirect correlation between the Fractal Index and the noise levels at the facades is expected.

One of the objectives of this study is the application of the relation between noise exposure of buildings and urban form, to promote the creation of protected areas or quiet zones in an urban context.

\section{Validation}

In order to give consistency to the theoretically developed curves, it is essential to validate the results. This procedure consisted of comparing the values obtained from modeling with measurement values taken at selected locations. The validation performed compared average values and all the analyses were done using average values.

The validation of the theoretical curves was made in two phases:

1. Validation of real models:

a. Selection of residential blocks with a configuration similar to the urban forms used in the theoretical curves (real forms).

b. Picking validation points (receiver points - Rcv) in each real form selected.

c. Counting traffic in the surrounding roads and noise level measuring at receiver points.

d. Modeling real models and calculation of noise at the receiver points.

e. Validation of the real models comparing measured and modeled noise levels at receiver points.

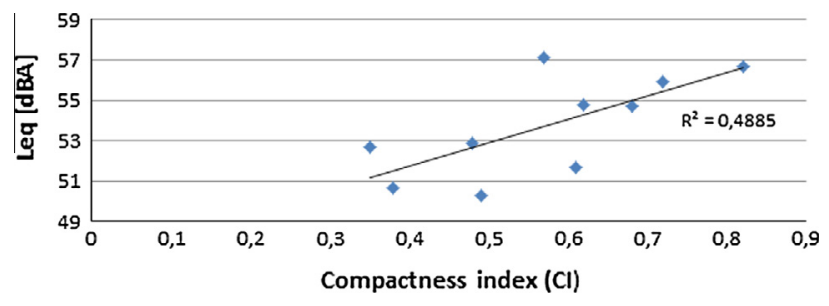

Fig. 3. Compactness index vs. average noise level facades.

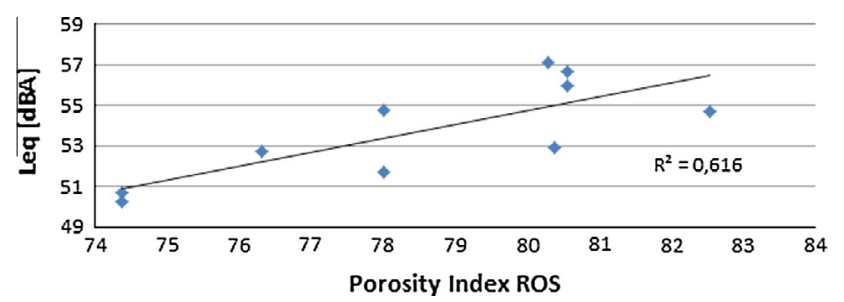

Fig. 4. Porosity index vs. average noise level facades.

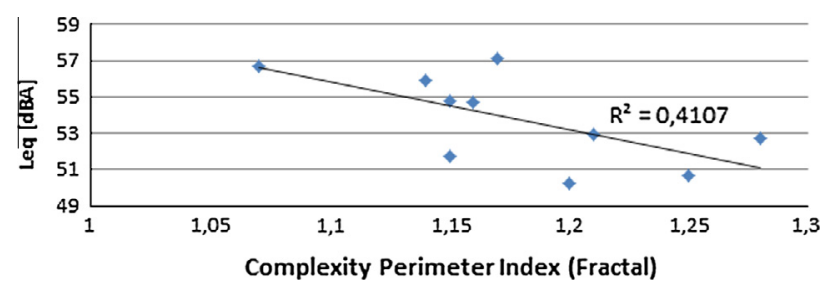

Fig. 5. Fractal vs. average noise level facades.

2. Validation of the theoretical curves:

a. Calculation of the average noise level on the modeled facade of the real forms, previously validated (Real Modeled Forms).

b. Calculation of form indicators of the real forms.

c. Setting the theoretical curves to the real models regarding the average traffic flow, traffic speed and type of pavement.

d. Validation of the similar behavior by comparison of the adjusted modeled and theoretical forms and measurements of the real context.

\subsection{Validation of real models}

Three urban forms were selected in Braga, a mid-sized city located on the northwest of Portugal. All of them are excerpts from residential areas taken from different parts of the city, as can be seen in Figs. 6-8. The real urban form illustrated in Fig. 6 is similar to the urban form 4 , the residential blocks in Fig. 7 have a similar configuration to the urban form 9 and blocks illustrated in Fig. 8 with a similar shape of urban form 10 .

In accordance with APA [32] and with NP 1730 [33] methodology, three measurements of 30 min each were carried out in points located around the buildings. The selection of the sites was undertaken according to the following criteria: exposed zones and quiet zones. The measurements were made on typical days and in each case the measurement height was $1.5 \mathrm{~m}$, carried out away from the facade of buildings $(4 \mathrm{~m})$ and reflective surfaces.

During the noise measurement, traffic counts were registered in the surrounding roads. A full survey, including topographic characteristics, sound absorption characteristics of the ground, presence of natural and artificial barriers, and the specification of the emission sources (profile, cross section and pavements of streets) was carried out for the three selected urban forms.

From the gathered data, the noise simulation model was used to evaluate the noise level at the receiver points and at the facades of the real forms.

The following calculation parameters were adopted:

- The evaluation of noise level at the receivers was made at points with the same location of the noise level measuring points (Rcv's).

- The evaluation of noise level at the facades was developed using a square calculation grid on all the facades of $1.5 \mathrm{~m} \times 1.5 \mathrm{~m}$ and a distance from the facade of $0.5 \mathrm{~m}$. 


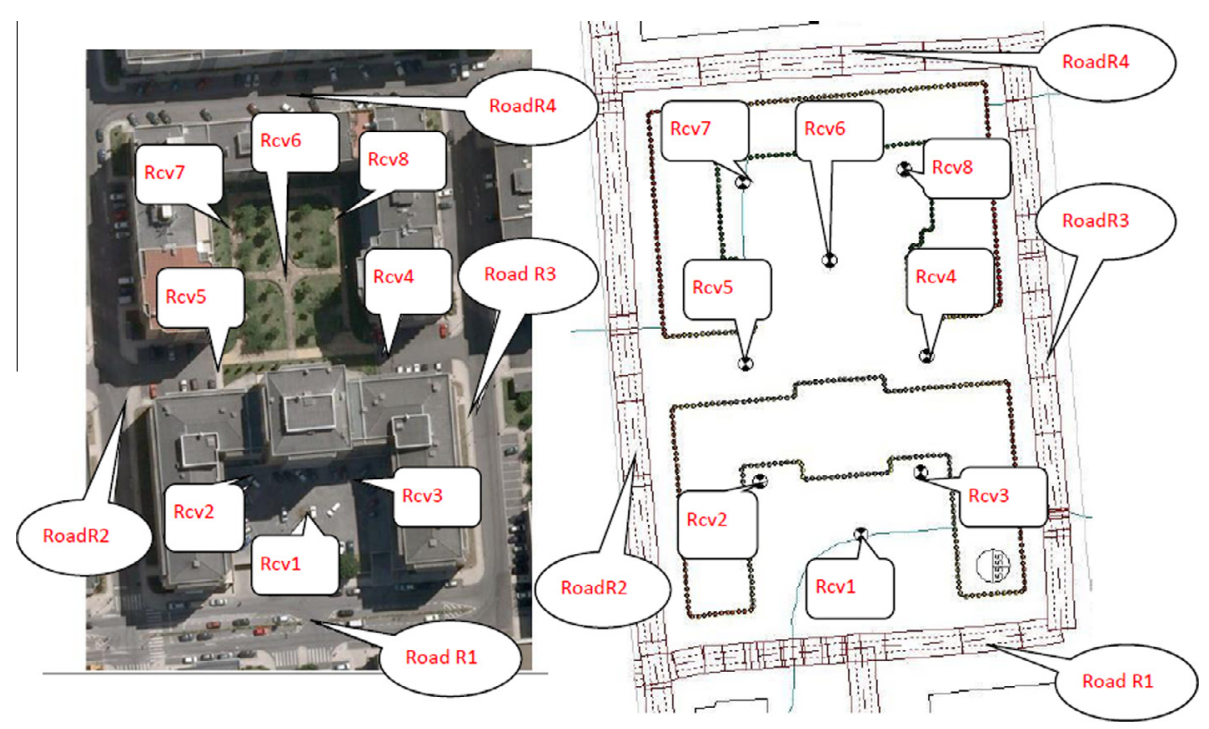

Fig. 6. Measured and modeled receiver points of real urban form 4 .
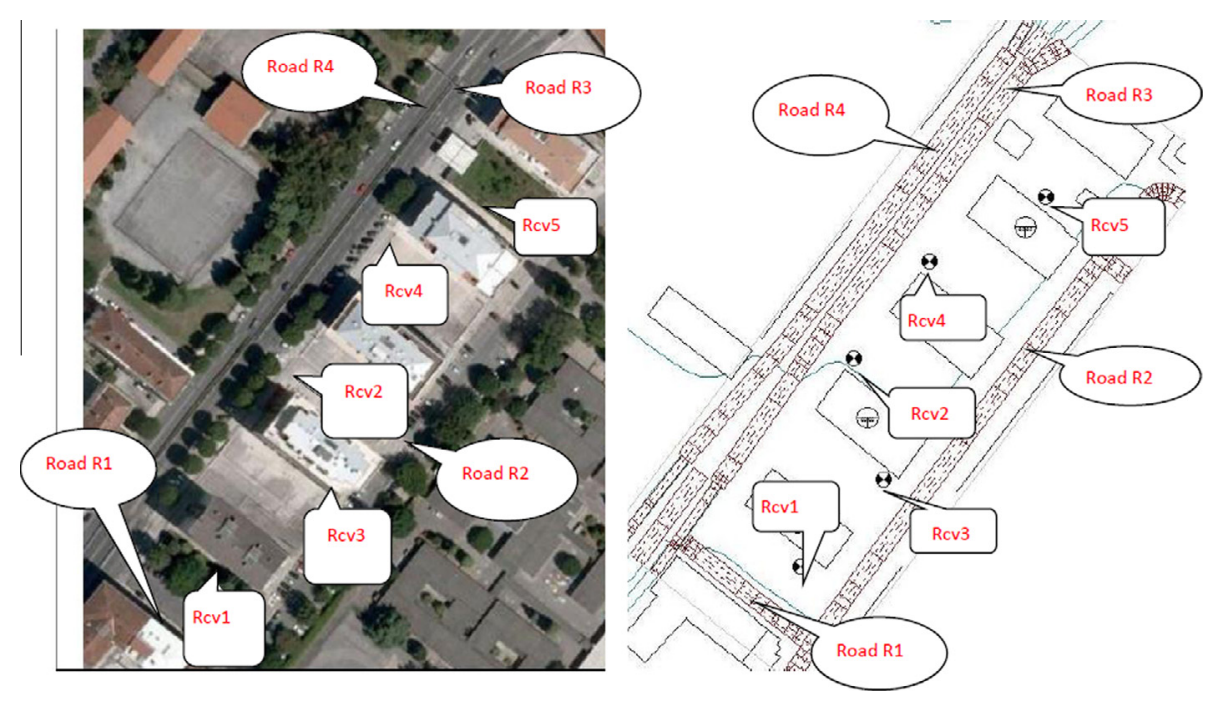

Fig. 7. Measured and modeled receiver points of urban form 9.

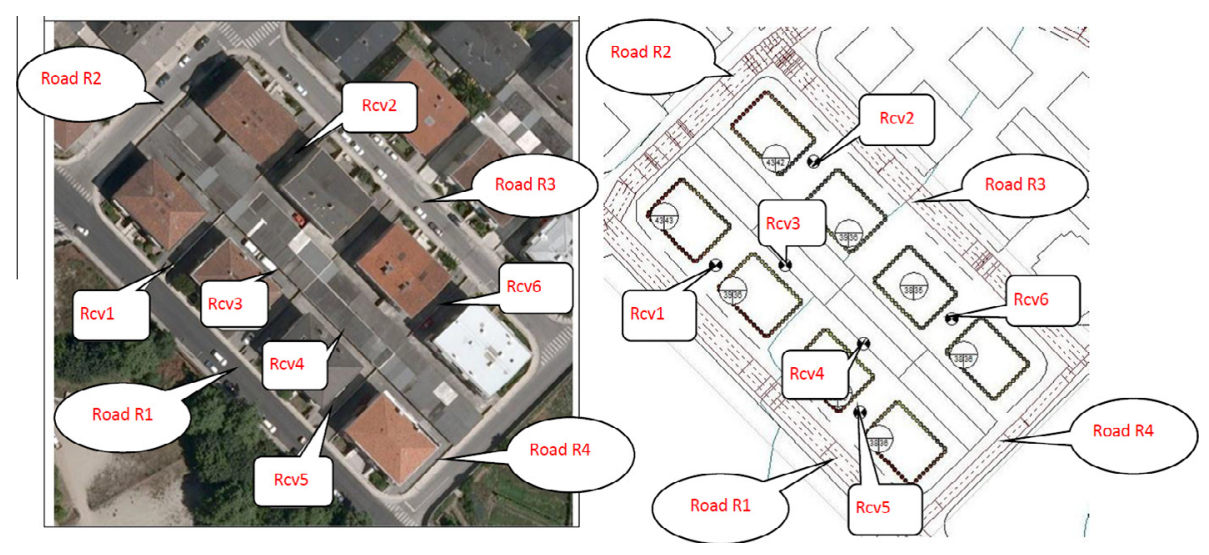

Fig. 8. Measured and modeled receiver points of real urban form 10 . 
Table 4

Measured and modeled receiver points of real urban form 4

\begin{tabular}{llll}
\hline Receivers & $\begin{array}{l}\text { Measured noise level } \\
\left(L_{e q}, \mathrm{dBA}\right)\end{array}$ & $\begin{array}{l}\text { Modeled noise level } \\
\left(L_{e q}, \mathrm{dBA}\right)\end{array}$ & $\begin{array}{l}\Delta \text { (absolute } \\
\text { value })\end{array}$ \\
\hline Rcv1 & 57.5 & 57.9 & -0.4 \\
Rcv2 & 54.8 & 50.2 & 4.6 \\
Rcv3 & 51.7 & 50.0 & 1.7 \\
Rcv4 & 52.6 & 52.7 & 0.1 \\
Rcv5 & 53.9 & 53.6 & 0.3 \\
Rcv6 & 50.1 & 48.6 & 1.5 \\
Rcv7 & 50.1 & 49.3 & 0.8 \\
Rcv8 & 50.2 & 49.4 & 0.8 \\
\hline
\end{tabular}

Table 5

Measured and modeled receiver points of urban form 9

\begin{tabular}{llll}
\hline Receivers & $\begin{array}{l}\text { Measured noise level } \\
\left(L_{\text {eq }}, \mathrm{dBA}\right)\end{array}$ & $\begin{array}{l}\text { Modeled noise level } \\
\left(L_{\text {eq }}, \mathrm{dBA}\right)\end{array}$ & $\begin{array}{l}\Delta \text { (absolute } \\
\text { value) }\end{array}$ \\
\hline Rcv1 & 65.0 & 65.1 & -0.1 \\
Rcv2 & 64.7 & 65.8 & -1.1 \\
Rcv3 & 59.5 & 58.9 & 0.6 \\
Rcv4 & 66.1 & 66.7 & -0.6 \\
Rcv5 & 58.9 & 59.6 & -0.7 \\
\hline
\end{tabular}

Table 6

Measured and modeled receiver points of real urban form 10 .

\begin{tabular}{llll}
\hline Receivers & $\begin{array}{l}\text { Measured noise level } \\
\left(L_{e q}, \mathrm{dBA}\right)\end{array}$ & $\begin{array}{l}\text { Modeled noise level } \\
\left(L_{\text {eq }}, \mathrm{dBA}\right)\end{array}$ & $\begin{array}{l}\Delta \text { (absolute } \\
\text { value) }\end{array}$ \\
\hline Rcv1 & 58.8 & 58.1 & 0.7 \\
Rcv2 & 48.4 & 48.7 & -0.3 \\
Rcv5 & 53.0 & 54.6 & -1.6 \\
Rcv6 & 46.0 & 45.9 & 0.1 \\
\hline
\end{tabular}

- Reflection order: 2.

- Output: $L_{e q}(\mathrm{~A})$.

- Road surface: Asphalt pavement; Average speed: $50 \mathrm{~km} / \mathrm{h}$.

- Favorable meteorological conditions to sound propagation.

- Temperature: $15^{\circ} \mathrm{C}$; Humidity: $70 \%$.

- The buildings in the three real urban forms with the following characteristics:

- Number of floors: 4 floors.

- Height of each floor:3 m (ground floor included).

- Total height of each building: $12 \mathrm{~m}$.

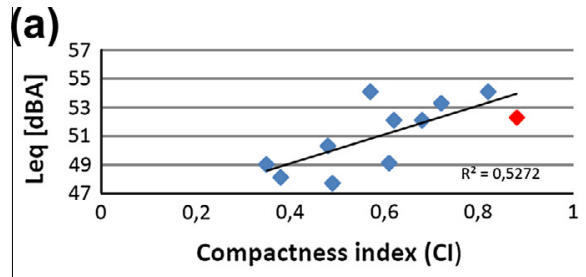

Tables 4-6 show the noise levels at the facades of the three real urban forms.

For the real urban form 4, the comparison of modeled and measured noise levels at the receiver points has confirmed an overall good performance of the model. In general, the model slightly underestimates noise. The point Rcv2 is the only one presenting considerable differences, due to the fact that there is another source of noise not accounted for.

In the case of real urban form 9, the values tend to be higher than the measured values as a result of some over-prediction in noise levels. The discrepancies are lower (in a range from 0.1 to 1.1 absolute values) but the noise levels found here are clearly higher than those in the other forms.

As can be seen in data from real urban form 10 (Table 6), six receiver points/measurement points were selected but only four are presented here to validate the model. As Rcv3 and Rcv4 were located very close to the building facades and garages, serious problems of reflection ( $U$ configuration) were encountered; hence these receivers were not included. The required distance of $4 \mathrm{~m}$ away from reflecting surfaces was not fulfilled in this case.

The first phase of validation was established, based on the values obtained for the receptor points by comparing the measured "in situ" values with the respective modeled values. The comparison of the average values of modeled and measured noise levels in the receiver points confirms the generally good performance of the three real modeled forms.

\subsection{Validation of the theoretical curves}

The validation of the theoretical curves intends to make use of the modeled traffic volume in each road of the real forms and distribute it by the actual number of roads, in order to obtain an average number of vehicles per hour.

In order to allow comparisons of the behavior of the three real forms in relation to the 10 modeled forms, it was necessary to proceed with the adjustment of the latter, with respect to the average traffic flow, traffic speed and type of pavement. Noise levels were calculated for the new traffic volumes for each of the 10 modeled forms. As for the traffic flow, the following adjustments were made:

- To be comparable with the Real Modeled Form 4, the two-lane traffic volume of the 10 modeled urban forms was 262 vehicles/h.

- To be comparable with the Real Modeled Form9, the two-lane traffic volume of the 10 modeled urban forms was 1343 vehicles/h.

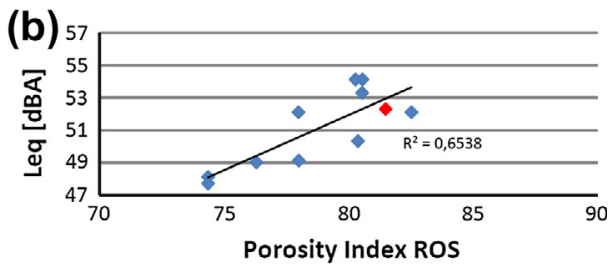

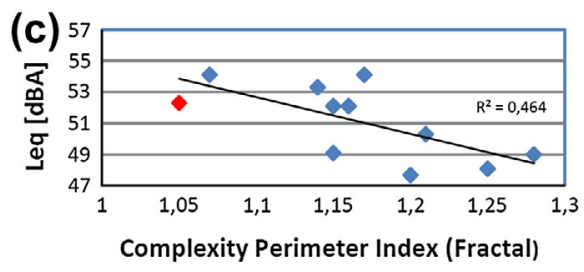

Fig. 9. Urban form indexes vs. average noise level facades (traffic volume - 262 vehicles/h). (a) CI vs. $L_{e q}$, (b) ROS vs. $L_{e q}$ and (c) fractal vs. $L_{e q}$. 
(a)

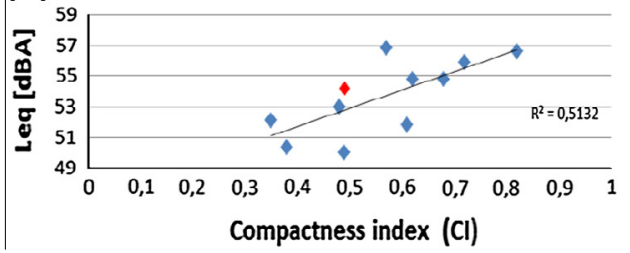

(b)

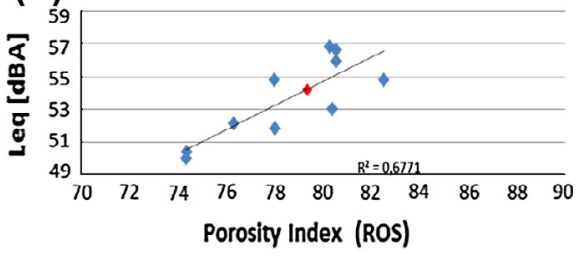

(c)

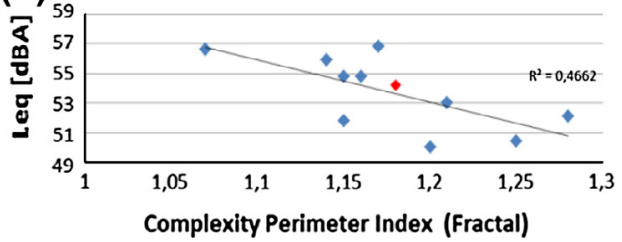

Fig. 10. Urban form indices vs. average noise level facades (traffic volume - 1343vehicles/h). (a) CI vs. $L_{e q}$, (b) ROS vs. $L_{e q}$ and (c) fractal vs. $L_{e q}$.

(a)

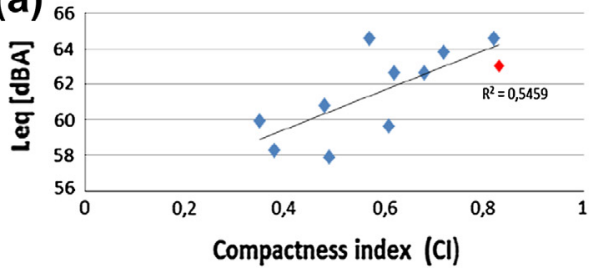

(b)

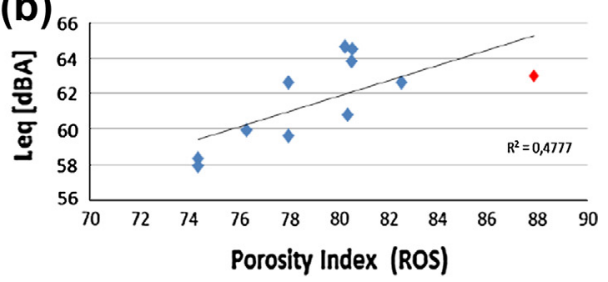

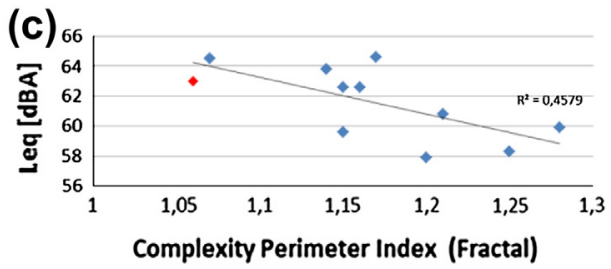

Fig. 11. Urban form indices vs. average noise level facades (traffic volume -167 vehicles/h). (a) CI vs. $L_{e q}$, (b) ROS vs. $L_{e q}$ and (c) fractal vs. $L_{e q}$.

Table 7

Urban form indices vs. average noise level facades (traffic volume - 262 vehicles/h).

\begin{tabular}{cllll}
\hline Urban form & $\begin{array}{l}\text { Average } \\
\text { noise } \\
\text { level } \\
\text { (dBA) }\end{array}$ & $\begin{array}{l}\text { Compactness } \\
\text { index (CI) }\end{array}$ & $\begin{array}{l}\text { Porosity } \\
\text { index } \\
\text { (ROS) }\end{array}$ & $\begin{array}{l}\text { Complexity } \\
\text { perimeter } \\
\text { index } \\
\text { (fractal) }\end{array}$ \\
\hline 1 & 48.1 & 0.38 & 74.37 & 1.25 \\
2 & 47.7 & 0.49 & 74.36 & 1.2 \\
3 & 50.3 & 0.48 & 80.38 & 1.21 \\
4 & 49.0 & 0.35 & 76.31 & 1.28 \\
5 & 52.1 & 0.62 & 78.00 & 1.15 \\
6 & 52.1 & 0.68 & 82.53 & 1.16 \\
7 & 53.3 & 0.72 & 80.55 & 1.14 \\
8 & 49.1 & 0.61 & 78.01 & 1.15 \\
9 & 54.1 & 0.57 & 80.28 & 1.17 \\
10 & 54.1 & 0.82 & 80.56 & 1.07 \\
Real modeled form 4 & 52.3 & 0.88 & 81.49 & 1.05 \\
\hline
\end{tabular}

- To be comparable with the Real Modeled Form10, the two-lane traffic volume of the 10 modeled urban forms was 167 vehicles/h.

Finally, the ordered pairs (form indicators vs. noise levels at the facade) of the 4, 9 and 10 real forms were introduced in the tendency curves of the 10 modeled forms, in order to establish a com-
Table 8

Urban form indices vs. average noise level facades (traffic volume - 1343 vehicles/h)

\begin{tabular}{cllll}
\hline Urban form & $\begin{array}{l}\text { Average } \\
\text { noise } \\
\text { level } \\
\text { (dBA) }\end{array}$ & $\begin{array}{l}\text { Compactness } \\
\text { index (CI) }\end{array}$ & $\begin{array}{l}\text { Porosity } \\
\text { index } \\
\text { (ROS) }\end{array}$ & $\begin{array}{l}\text { Complexity } \\
\text { perimeter } \\
\text { index } \\
\text { (fractal) }\end{array}$ \\
\hline 1 & 50.4 & 0.38 & 74.37 & 1.25 \\
2 & 50.0 & 0.49 & 74.36 & 1.20 \\
3 & 53.0 & 0.48 & 80.38 & 1.21 \\
4 & 52.1 & 0.35 & 76.31 & 1.28 \\
5 & 54.8 & 0.62 & 78.00 & 1.15 \\
6 & 54.8 & 0.68 & 82.53 & 1.16 \\
7 & 55.9 & 0.72 & 80.55 & 1.14 \\
8 & 51.8 & 0.61 & 78.01 & 1.15 \\
9 & 56.8 & 0.57 & 80.28 & 1.17 \\
10 & 56.6 & 0.82 & 80.56 & 1.07 \\
Real modeled form 9 & 54.2 & 0.49 & 79.35 & 1.18 \\
\hline
\end{tabular}

parison between the adjusted models and the real urban forms. Figs. 9-11 illustrate the tendency curves and the red highlighted points indicate the real forms.

The behavior of the noise level of each of the real forms in relation to their theoretical models experienced no significant discrepancies or variations in the parameters of vehicle traffic, where the adjustment of the number of vehicles per hour was varied by 
Table 9

Urban form indices vs. average noise level facades (traffic volume -167 vehicles/h)

\begin{tabular}{cllll}
\hline Urban form & $\begin{array}{l}\text { Average } \\
\text { noise } \\
\text { level } \\
\text { (dBA) }\end{array}$ & $\begin{array}{l}\text { Compactness } \\
\text { index (CI) }\end{array}$ & $\begin{array}{l}\text { Porosity } \\
\text { index } \\
\text { (ROS) }\end{array}$ & $\begin{array}{l}\text { Complexity } \\
\text { perimeter } \\
\text { index } \\
\text { (fractal) }\end{array}$ \\
\hline 1 & 58.3 & 0.38 & 74.37 & 1.25 \\
2 & 57.9 & 0.49 & 74.36 & 1.2 \\
3 & 60.8 & 0.48 & 80.38 & 1.21 \\
4 & 65.0 & 0.35 & 76.31 & 1.28 \\
5 & 62.6 & 0.62 & 78.00 & 1.15 \\
6 & 62.6 & 0.68 & 82.53 & 1.16 \\
7 & 63.8 & 0.72 & 80.55 & 1.14 \\
8 & 59.6 & 0.61 & 78.01 & 1.15 \\
9 & 64.6 & 0.57 & 80.28 & 1.17 \\
10 & 64.5 & 0.82 & 80.56 & 1.07 \\
Real modeled form 10 & 63.0 & 0.83 & 87.85 & 1.06 \\
\hline
\end{tabular}

changing the behavior of the noise with regard to the urban form. This is not only the volume or composition of road traffic that alone changes the behavior of noise, but also the volumetric composition forming a neighborhood unit.

In other words, the volumetry of the proposed neighborhood units, represented by the 10 types of urban forms, with its complexities and protrusions, can promote or not the existence of protected areas or shadow zones, which can per se decrease or increase, respectively, the exposure to noise in their respective facades. This means that the applied methodology allowed obtaining the proposed results, that is, validated the similar behavior of modeled and theoretical forms, by comparison between the adjusted models and the real urban forms.

\section{Conclusions}

In the first forms, it was always possible to relate permeability/ openings of buildings and interior/exterior of blocks and the respective effects of noise in their facades. On the other hand, in the last two forms, this was not possible, because there is no layout allowing for the analysis of the interior of a block and thus for the evaluation of its change and influence in noise levels. It is possible to conclude that the studied forms 1,2 , and 8 correspond to lower noise levels, since these include more protected areas. This effect is provided by the existence of the interior of the block, which, as already mentioned, concentrates the shadow areas, which in turn reduce the exposure to noise levels at the facades.

On the contrary, forms 7, 9 and 10 are those with the highest levels of noise, where no obstacles can be found to noise propagation. Thus, it is difficult to create protected areas or shadow zones. From the analysis of Figs. 9-11 and Tables 7-9 it is possible to say that there is an increase of noise levels as ROS increases. This relation can be translated, for example, by an increase of $6 \mathrm{dBA}$ for an increase of $8 \%$ in ROS. This conclusion highlights the potentiality of this index as planning tool to be used for the regulation for new building constructions. The ROS index of the building blocks is a common parameter for design approval in public regulation agencies, although it has never been considered as an acoustical tool.

Considering the compactness index, as shown in Figs. 9-11, a change from the lowest $\mathrm{CI}$ (approximately 0.4 ) to the highest value (close to 0.7 ) induces an increase of $6 \mathrm{dBA}$

Additionally, from the fractal results in Figs. 9-11, a change from the highest (close to 1.2) to the lowest fractal (1.1) produces an increase of noise levels of $6 \mathrm{dBA}$. These findings also suggest that these indexes should assume an acoustical profile on building regulations.

In the present study the noise descriptor used was the arithmetic average of equivalent noise level in each receiver, representing the average of noise level in each building. The analysis of maximum and minimum noise levels was not considered here. However, this is an area where further analysis could be considered in the future.

This research study allowed the creation of different scenarios and enabled anticipating early at the conception stage which of the facades would have higher exposure to noise. Therefore, it is possible to minimize in advance the effects of noise in the facades, using the adjustment of the layout and configuration of the building form.

\section{References}

[1] United States Environmental Protection Agency. Our built and natural environments: a technical review of the interactions between land use, transportation and environmental quality (EPA 231-R-01e002). Washington DC, US: US EPA; 2001.

[2] World Health Organization (United Kingdom). Noise and health. London; 2000.

[3] Directive 2002/49/EC of the European Parliament and of the Council of June. Off J Eur Comm; 2002. p. 12-25.

[4] Decreto-Lei no. 9/2007. Diário da República. I Série-A, vol. 263. Lisboa, Portugal, 17 de Janeiro de 2007. p. 389-98.

[5] Torija A, Genaro N, Ruiz D, Ramos-Ridao A, Zamorano M, Requena I. Priorization of acoustic variables: environmental decision support for the physical characterization of urban sound environments. Build Environ 2009;45(2010):1477-89.

[6] Björkman M. Community noise annoyance: importance of noise levels and the number of noise events. J Sound Vibr 1991;151(3):497-503.

[7] Lercher P. Environmental noise and health: an integrated research perspective. Environ Int 1996;22(1):117-8.

[8] National Physical Planning Agency. Summary of the fourth report extra on physical planning. The Hague, The Netherlands: Ministry of Housing, Physical Planning and Environment; 1991

[9] Tang UW, Wang ZS. Influences of urban forms on traffic-induced noise and air pollution: results from a modelling system. J Environ Modell Soft 2007;22:1750-64.

[10] Lee S, Chang S, Park Y. Utilizing noise mapping for environmental impact assessment in a downtown redevelopment area of Seoul, Korea. Appl Acoust 2008;69(8):704-14. ISSN 0003-682X.

[11] Guedes I. Influência da forma urbana em ambiente sonoro: Um estudo no bairro jardins em Aracaju. Dissertação de Mestrado apresentada à Comissão de Pós-graduação da Faculdade de Engenharia Civil. Arquitetura e Urbanismo da Universidade Estadual de Campinas; 2005.

[12] Guedes ICM, Bertoli SR, Zannin PHT. Influence of urban shapes on environmental noise: a case study in Aracaju - Brazil. Sci Total Environ 2011;412-413:66-76.

[13] Oliveira MF, Silva LT. The influence of urban form on façade noise levels. WSEAS Trans Environ Develop 2011:7(5):2.

[14] Oliveira MF, Silva LT. How urban noise can be influenced by the urban form. Adv Biol Bioeng Environ 2011 [ISBN:978-960-474-261-5].

[15] Salomons EM, Pont MB. Urban traffic noise and the relation to urban density, form and traffic elasticity. Landscape Urban Plann 2012:108:2-16.

[16] Wang B, Kang J. Effects of urban morphology on the traffic noise distribution through noise mapping: a comparative study between UK and China. Appl Acoust 2011;72:556-68.

[17] Souza LC, Giunta MB. Urban indices as environmental noise indicators Comput Environ Urban Syst 2011;35:421-30.

[18] Torrens PM, Marina A. Measuring sprawl. London: Centre for Advanced Spatial; 2000.

[19] Wassmer RW. Urban sprawl in a US Metropolitan Area: ways to measure and a comparison of the Sacramento Area to Similar Metropolitan Areas in California and the US Project Paper; 2000.

[20] Galster G, Hanson R, Ratcliffe MR, Wolman H, Coleman S, Freihage J. Wrestling sprawl to the ground: defining and measuring an elusive concept. Hous. Pol. Debate 2001;12(4):681-717.

[21] Ewing R, Pendall R, Chen D. Measuring sprawl and its impact. Smart Growth America. Washington, DC; 2002.

[22] Tsai YH. Quantifying urban form: compactness versus 'Sprawl'. Urban Stud 2005;42(1):141-61.

[23] Longley PA, Mesev V. On the measurement and generalization of urban form. Environ Plann A 2000;32:473-88.

[24] Li X, Yeh AG. Analyzing spatial restructuring of land use patterns in a fast growing region using remote sensing and GIS. Landscape Urban Plann 2004;69:335-54.

[25] Huang J, Lu XX, Sellers JM. A global comparative analysis of urban form: applying spatial metrics and remote sensing. Landscape Urban Plann 2007:82:184-97.

[26] Bennion M, O’Neill W. Building transportation analysis zones using geographic information systems. Transport Res Record 1994;1429:49-56.

[27] Sanches SP. Definição de zonas de tráfego, a partir de setores censitários usando um SIG. In: Anpet - Congresso de Pesquisa e Ensino em Transportes 1997, 11, Rio de Janeiro. Anais, Rio de Janeiro, Brasil, v.1; 1997. p. 103-12. 
[28] Pedro JB. Programa Habitacional. Vizinhança Próxima, Lisboa: LNEC. Informações Científicas e Técnicas de Arquitectura, ITA 7; 1999. [ISBN:97249-1814-9].

[29] ISO 1996-2. Acoustics - description and measurement of environmental noise - Part 2: acquisition of data pertinent to land use, ISO/TC 43/SC $1 ; 1987$.

[30] OECD. Roadside noise abatement. Paris, France: Organisation for Economic Cooperation and Development Publications; 1995.

[31] Bertellino F, Licitra G. In Modelli Previsionali per il Rumore da Traffico Stradale In: Proc. of the Atti 2000 Convegno Nazional e Traffico e Ambiente 2000 Trento, Italia: Progetto Trento Ambiente; 2000. p. 63-82.
[32] APA. Directrizes para a elaboração de mapas de ruído. Versão 2. Portugal: Agência Portuguesa do Ambiente; 2008.

[33] Norma Portuguesa 1730. Acústica, descrição e medição de ruído ambiente Parte 1: Grandezas fundamentais e procedimentos; Parte 2: Recolha de dados relevantes para o uso do solo; Parte 3: Aplicação aos limites do ruído. Lisboa; 1996. 